\title{
The effectiveness of home visiting as a delivery strategy for public health nursing interventions to clients in the prenatal and postnatal period: a systematic review
}

Donna Ciliska McMaster University, School of Nursing, and Hamilton-Wentworth Social and Public Health Services, Hamilton, Paula Mastrilli St Joseph's Hospital, Toronto, Jenny Ploeg McMaster University, School of Nursing, and Hamilton-Wentworth Social and Public Health Services, Hamilton, Sarah Hayward Alberta Heritage Foundation for Medical Research, Alberta, Canada, Ginny Brunton Hamilton-Wentworth Social and Public Health Services, Hamilton and Jane Underwood McMaster University, School of Nursing, and Hamilton-Wentworth Social and Public Health Services, Hamilton, Ontario, Canada

\begin{abstract}
The purpose of this systematic overview was to assess the evidence for the effectiveness of public health nursing interventions when carried out by the strategy of home visiting of clients in the pre- and postnatal period. This is an update of a larger overview first collecting literature to 1993, then updated to the end of 1995, and now updated to 1998. The search of published and unpublished literature related to home visiting resulted in retrieval of a total of 211 articles, including 149 articles relevant to all age groups and including all interventions implemented by various professional and nonprofessional groups, where the intervention was considered to be within the scope of practice of public health nursing in Ontario. When the relevance was limited to interventions where the intervenor was known to be a nurse, and the clients were in the pre- or postnatal period, there were 20 articles with quality ratings of 'strong' or 'moderate' included in this update for the systematic review, and 8 additional articles in this update. There were no reported negative effects of home visiting in the 12 strong articles. Positive outcomes included improvement in children's mental development, mental health and physical growth, reduction in the mother's depression, improvement in maternal employment, education, nutrition and other health habits, and government cost saving. There is no proven impact on low birth weight, gestational age or neonatal morbidity or mortality, although the studies had inadequate sample sizes to demonstrate a difference in such relatively rare occurrences. As a delivery strategy, nurses visiting pre- and postnatal clients in the home can produce significant benefit, particularly with interventions of high intensity and with clients who are considered to be 'at risk' due to factors such as low income and low educational achievement.
\end{abstract}

Key words: effectiveness; home visiting; newborn; nursing; postnatal; prenatal; public health; review

\section{Introduction}

Historically, in North America, programmes for prenatal and postnatal women, newborn and early

Address for correspondence: Dr D. Ciliska, HSC 3H48, McMaster University, 200 Main Street West, Hamilton, Ontario, Canada L8N 3Z5. Email: ciliska@mcmaster.ca

(C)Arnold 2001 childhood care have been delivered by the strategy of public health nurses visiting the family in the home. Increasing fiscal restraint in the past 10 years led some health departments to abandon home visiting as it was considered to be too expensive. While multiple other delivery strategies have been developed, including peer and lay support workers, telephone information and support lines, and clinics, there is usually a certain pro1463-4236(2001)PC046OA 
portion of the population that does not access these alternative services. Thus home visiting remains one of a number of programme delivery strategies.

By reviewing and summarizing the findings of research studies, it is hoped that the most effective and efficient use of public health resources can be promoted by abandoning interventions for which there is evidence of no benefit, or evidence of harm, and by implementing interventions for which there is evidence of benefit. There are inherent difficulties in conducting research in community health (Hayward et al., 1996), including problems achieving large enough sample sizes for adequate power, conducting a randomized trial within a community, controlling for contamination and confounders, blinding outcome assessment, and finding reliable and valid outcome measurement tools. However, this review did find studies of high quality which will be presented here. This study is an update of a larger overview first collecting literature up to 1993 (Ciliska et al., 1996), and then updated to the end of 1998. It is acknowledged that a home visit may include many different types of intervention and, where possible, some detail is given in this paper about the content of the home visit.

The following question was asked for this systematic review. What is the effectiveness of public health nursing interventions for prenatal and postnatal clients offered through the strategy of home visiting?

Comparisons of interest relate to the risk level of clients and to the timing and intensity of the interventions.

\section{Methods}

\section{Search strategy}

1) For the overall project, an online search of MEDLINE and CINAHL was conducted for the years 1979 to 1998 . Key words used were 'PHN' or 'CHN', and 'effectiveness' or 'comparative' or 'control' or 'evaluative' study. A focused search using the keyword 'home visiting' was made back to 1985 .

2) Prominent authors in the field were searched online for the years 1986 to 1998.

3) Key public health journals were hand-searched from 1990 to 1998. These journals included the Canadian Journal of Public Health, the Canadian Journal of Nursing Research, the American Journal of Public Health, Nursing Research, Image, School Health, Journal of Advanced Nursing, Journal of Community Health Nursing, Public Health Nursing, and the American Journal of Health Promotion.

4) Published bibliographies, reports from several health research programmes and several government documents were hand-searched for relevant articles. The abstracts of workshops and papers presented at recent Canadian Public Health Association, Ontario Public Health Association and American Public Health Association conferences and the International Conference on Community Health Nursing were reviewed. Key informants were contacted in Public Health Research Education and Development Programs in Ontario, University Schools of Nursing in Canada and through a directory of Canadian Nurse Researchers, for both published and unpublished papers.

5) The content lists of 107 related journals were also reviewed monthly from September 1992 to December 1998.

6) Relevant references (from 1980 to the end of 1998) from each article were identified, retrieved and reviewed.

An article was retrieved as being of potential relevance if its title or abstract indicated that it was an evaluative study of an intervention, within the scope of public health nursing, conducted in the home with clients of any age group. For online searches, two reviewers independently assessed the bibliographic listings. For all other sources of retrieval, one reviewer assessed material for its potential relevance.

\section{Review procedures}

The relevance criteria determined whether the study evaluated an intervention or programme, described an intervention within the scope of public health nursing (PHN) practice in Canada (Canadian Public Health Association, 1990), provided information on client-focused outcomes and/or cost, described a prospective study and had a control or comparison group (which could have been before and/or after the study). To be included, an article had to meet all five inclusion criteria. In the initial overview and update, articles were

Primary Health Care Research and Development 2001; 2: 41-54 
considered relevant regardless of the discipline or preparation of the intervenor, if the intervention was within the scope of PHN practice in Ontario. For this update, the relevance criteria included only those studies in which the intervenor was identified as a nurse. An additional limiting relevance criterion was that the target group had to consist of prenatal and/or postnatal clients. These criteria were agreed upon by the authors after extensive consultation with practitioners and policy-level personnel within Public Health Departments and the consultant within the Ministry of Health of Ontario. They were considered to be criteria which would result in a review with greatest applicability to decisions regarding resource allocation practice patterns. The educational preparation of the 'nurse' was often not made explicit in the studies.

The next phase involved rating the relevant articles for validity. A validity tool was developed using the Cochrane tool (Oxman, 1992) as a starting point, and it was then pre-tested and modified. It included the following criteria: method of allocation to the study groups; level of agreement to participate in the study; control for confounders; method of data collection (pre-testing of data collection tools, blinding of data collectors to group allocation of study participants); quantitative measure of effect; cost analysis; and percentage of participant follow-up. Studies were rated as 'pass', 'moderate' or 'fail' on each criterion. If an article stated that the sample was 'randomized' without providing any information about how that was achieved, it was considered to be quasi-randomized, which satisfied the 'moderate' rating. The tool was tested for inter-rater reliability and it achieved a kappa score of at least 0.80 with three sets of two readers independently rating articles.

In order for an article to be assessed as 'strong', a minimum of four of six criteria had to be rated as 'pass' with no 'fail'. For the 'moderate' category, no criterion could be a 'fail' and three or more criteria had to be 'moderate'. A 'weak' rating meant that at least one criterion was a 'fail'. For this update, all of the articles were read and rated independently by two reviewers, each of whom was blind to the rating of the other person, both for relevance and for validity. Any discrepancies were discussed until a consensus was reached. The primary reader did the data abstraction.

The most frequent weaknesses were that the method of allocation to study groups was not random, that the method of randomization was not described, that there was inadequate control for potential confounders, and that less than $80 \%$ of potential participants actually participated.

The purpose and content of the interventions in these studies were highly diverse. There were various different populations, different outcomes, and different ways of measuring the same outcomes. For these reasons, the authors decided that a metaanalysis would not be meaningful.

\section{Results}

The total search of published and unpublished literature related to home visiting resulted in retrieval of 211 articles, of which 149 articles were relevant to all age groups, and including all interventions done by various professional and nonprofessional groups, where the intervention was considered to be within the scope of practice of public health nursing in Ontario. When the relevance was limited to interventions where the intervenor was known to be a nurse, and the clients were in the pre- or postnatal period, there were 15 articles (rated as strong and moderate) from the previous update included in this review. A total of 10 additional articles from this update were relevant to the narrower question, and five were rated as weak on quality. Therefore there were 20 articles for this systematic review, and 8 articles added since the last review.

Table 1 summarizes the 20 articles (12 strong and 11 moderate) related to 12 studies, including the design, intervention and results. It is important to note that there are two studies with more than one article, which are different reports concerning different follow-up times or different outcomes for the same study. These include the initial study by Rauch et al. (1988) of low-birth-weight babies and the two longer follow-ups at 7 years (Achenbach et al., 1990) and 9 years (Achenbach et al., 1993), as well as the seven total reports of the Elmira study of Olds and colleagues beginning with the two initial reports (Olds et al., 1986a; 1986b), followed by the 2-year follow-up (Olds et al., 1988; Olds, 1993), 4-year follow-up (Olds et al., 1994) and 15-year follow-up (Olds et al., 1997; 1998).

The studies are grouped according to interventions in the prenatal period and the postnatal period and interventions that took place in both 


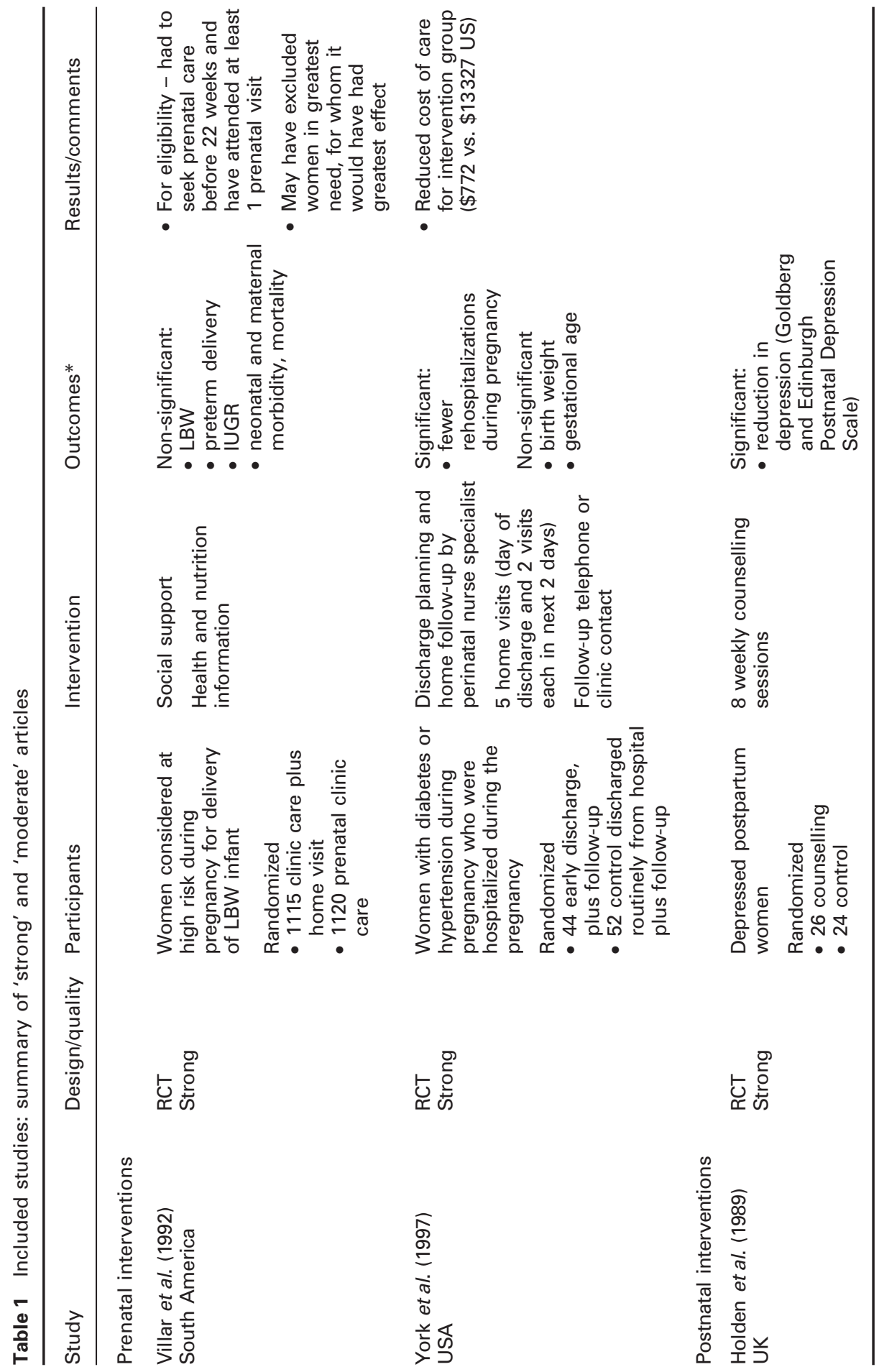

Primary Health Care Research and Development 2001; 2: 41-54 


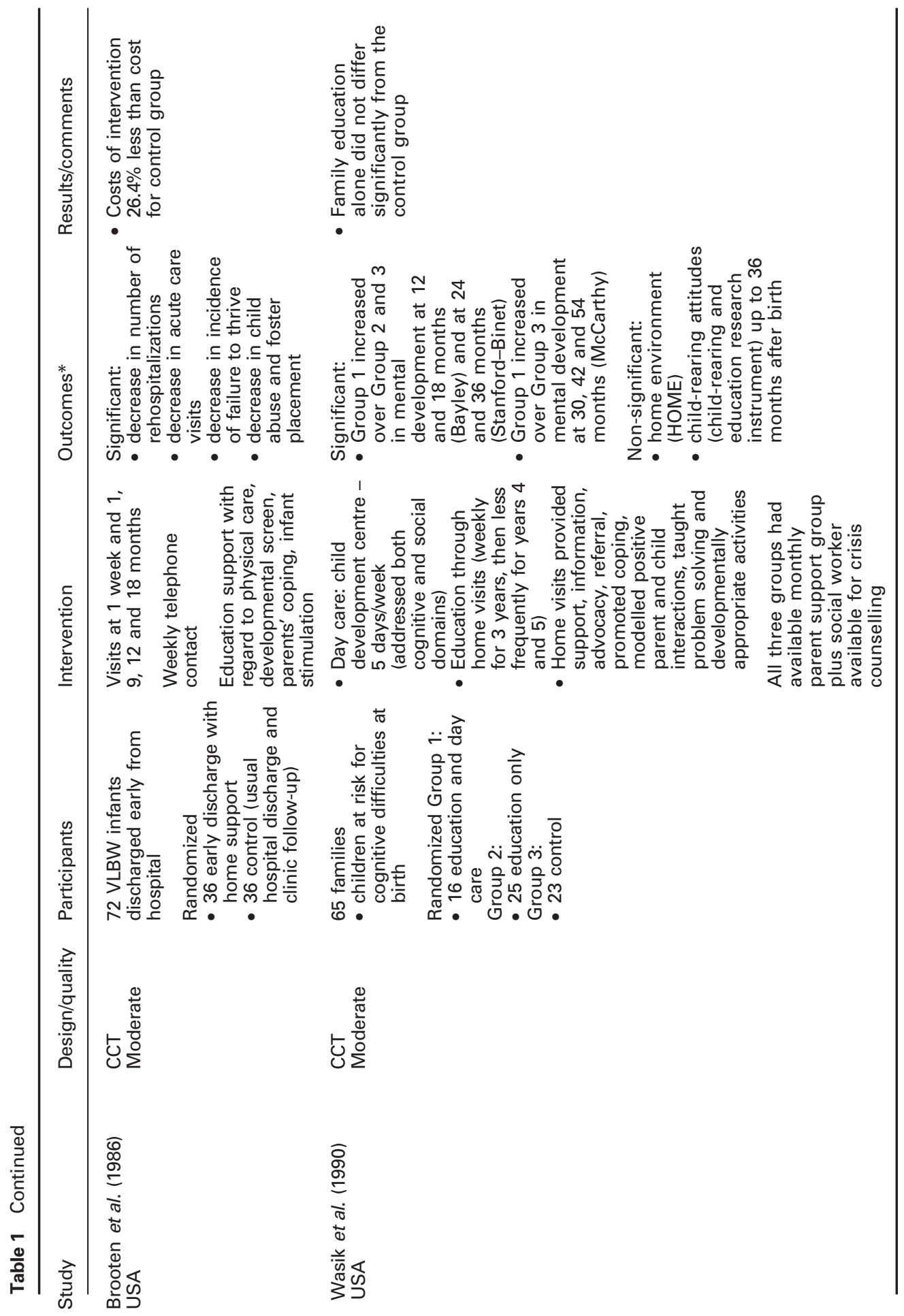

Primary Health Care Research and Development 2001; 2: 41-54 


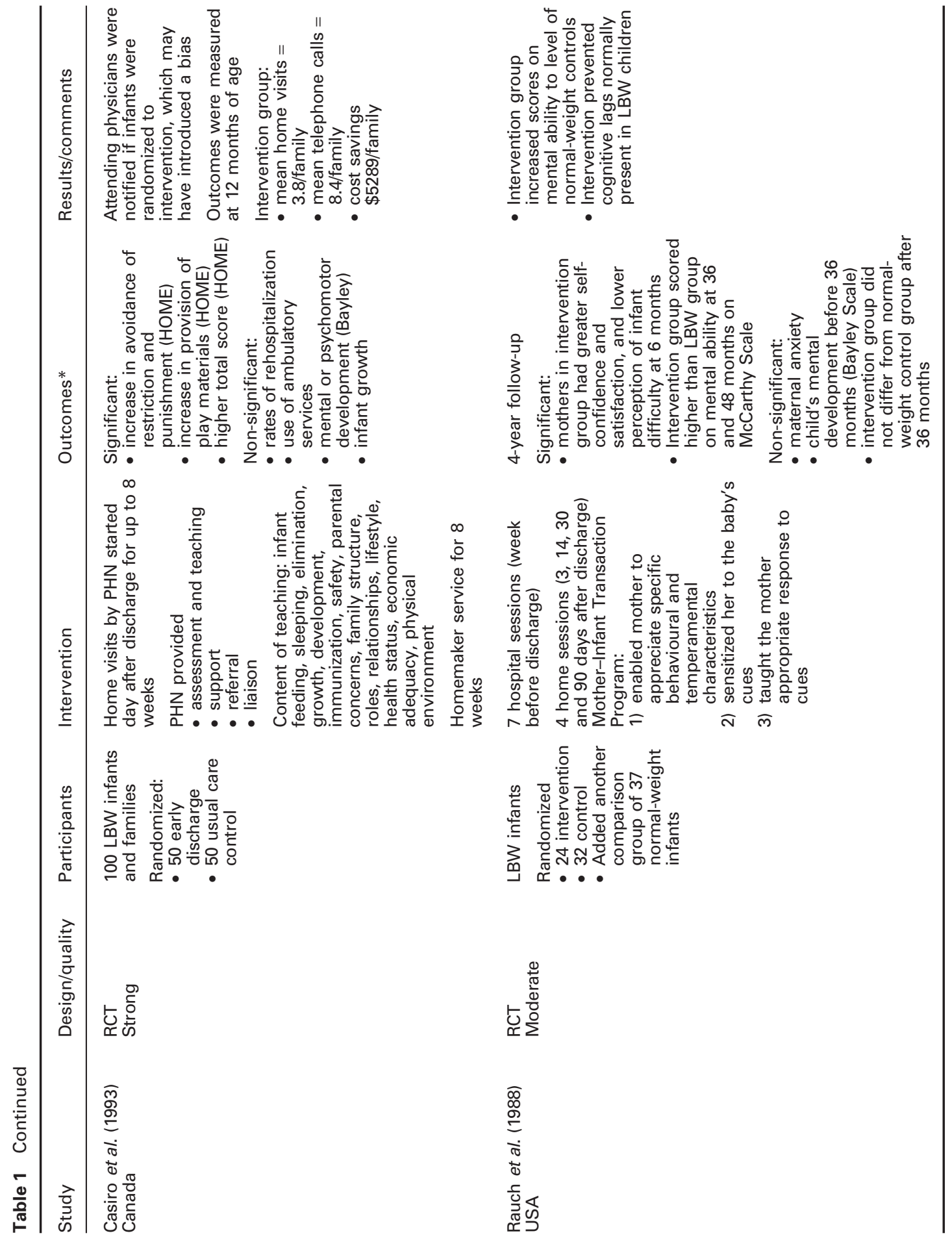

Primary Health Care Research and Development 2001; 2: 41-54 


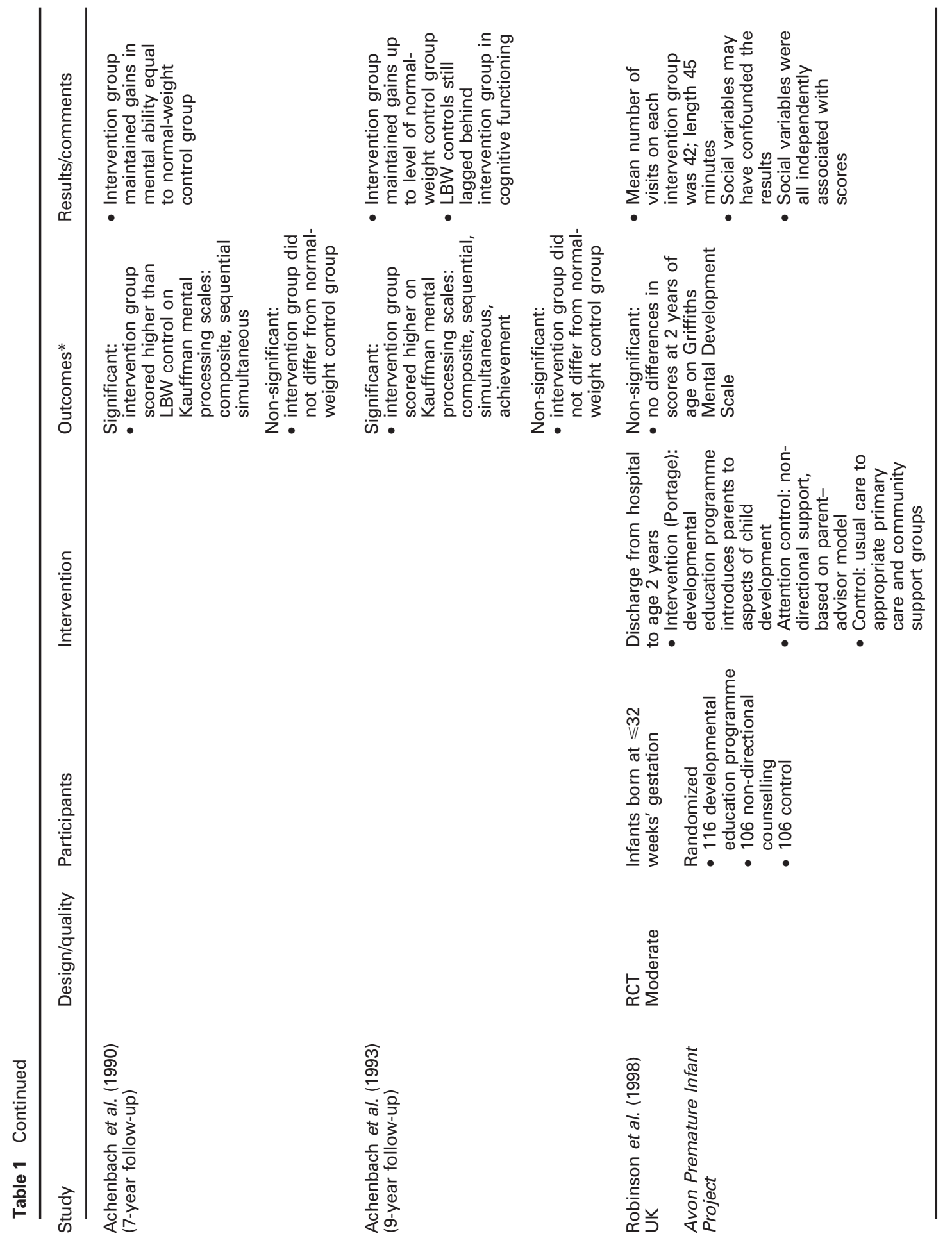

Primary Health Care Research and Development 2001; 2: 41-54 

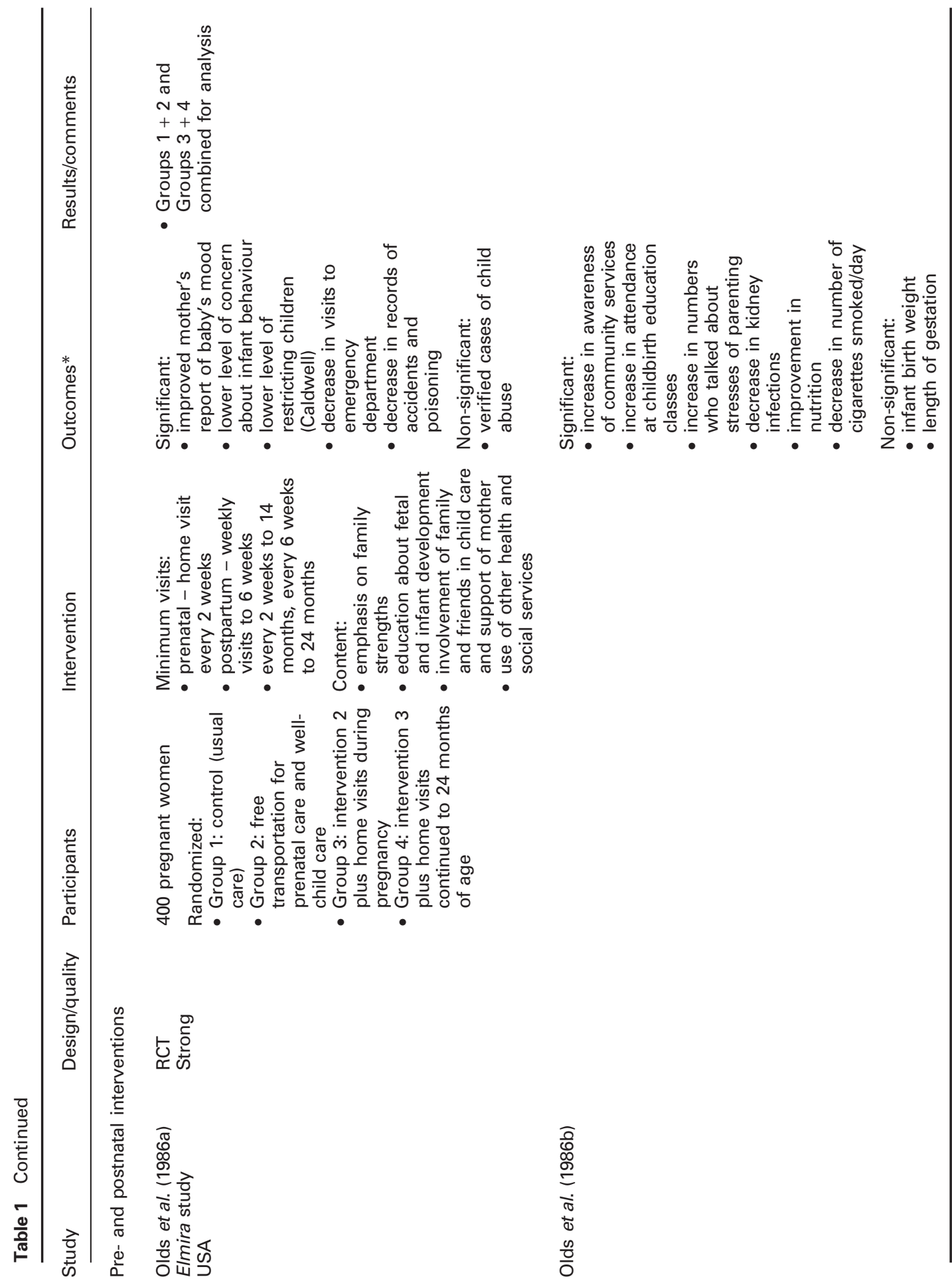

$\frac{0}{0}$
0
$\frac{0}{5}$
$\frac{0}{\pi}$
$\frac{0}{0}$
$\frac{0}{0}$
$\frac{0}{0}$

Primary Health Care Research and Development 2001; 2: 41-54 


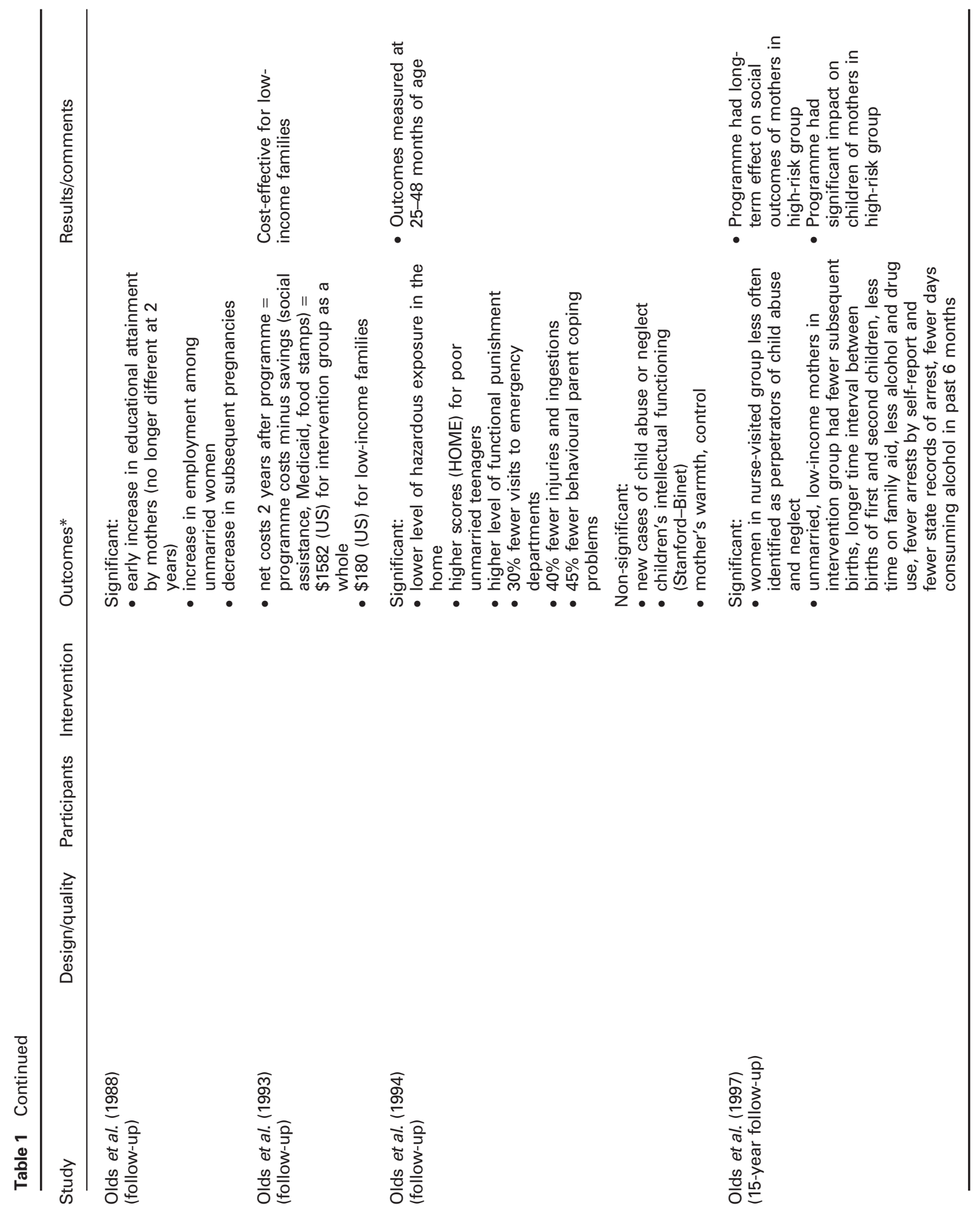

Primary Health Care Research and Development 2001; 2: 41-54 


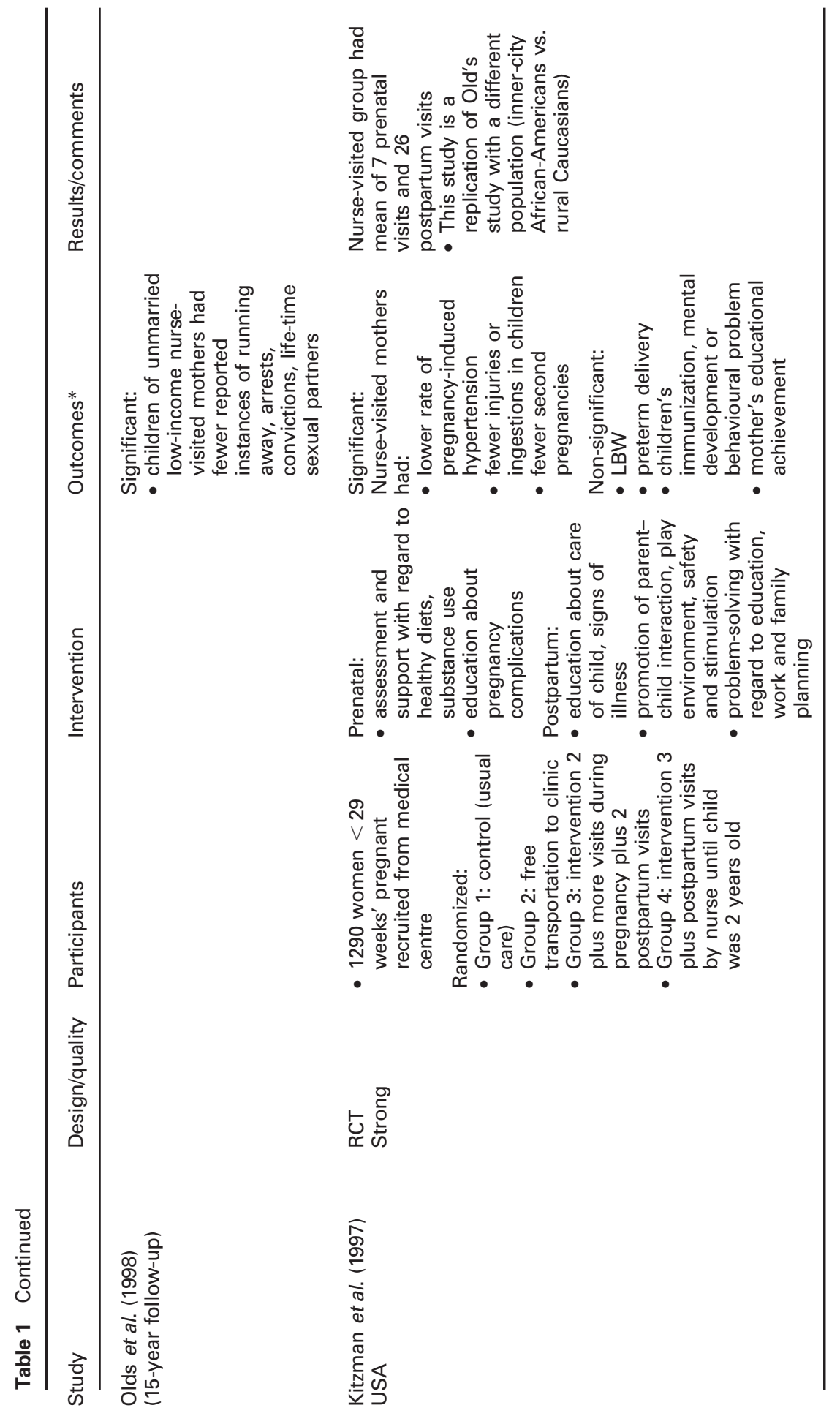

Primary Health Care Research and Development 2001; 2: 41-54 


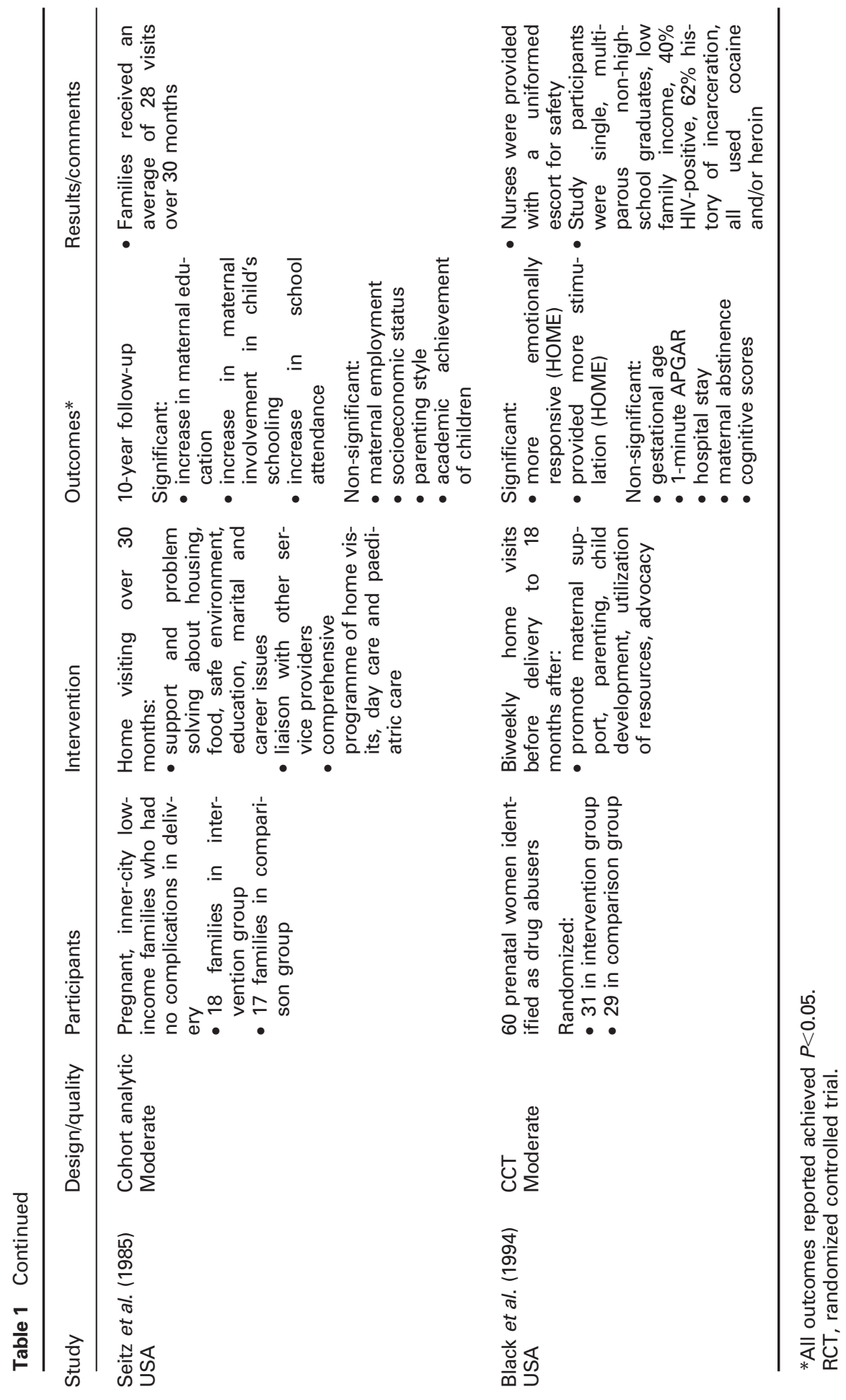

Primary Health Care Research and Development 2001; 2: 41-54 
pre- and postnatal period with the same client. For narrative detail about the studies included, see Ciliska et al. (1999).

\section{Discussion}

The additional eight studies in this update, added to the original 12 studies, continue to confirm the earlier review findings. In summarizing the literature, there are no negative effects of home visiting - that is, home visits have not been shown to do any harm. There were no outcomes reported where the non-home-visited group were worse off with regard to the intervention than the control group. Moreover, the studies have demonstrated a positive impact of nurses intervening through the delivery strategy of home visiting on physical health, mental health and development, social health, health habits, and knowledge and service utilization of mothers and babies. Home visiting can have a positive impact on the quality of the home environment, a finding that was also confirmed in the recent review by Kendrick et al. (2000a). Home visiting can increase the effectiveness of other medical, social and educational services. Some of the articles report no effect or else selective effects, but the effects seem to be mediated by the intensity of the intervention and the pre-existing level of health and social status of the client. Larger treatment differences were associated with higher intensity of the intervention. Effectiveness can be impaired by inadequate intensity or poor timing of home visits. Interventions generally had more impact on clients at higher risk (e.g., unmarried clients, those on low income, teenage mothers) than on those at moderate or low risk. The exception to the findings in high-risk groups is the study of young pregnant women who were multiple drug users (Black et al., 1994).

Home visiting has shown no impact on some outcomes. For example, there is no evidence that home visiting increases the uptake of immunization (Kendrick et al., 2000b). There is also no evidence of an effect of prenatal programmes delivered by nurses through home visiting on low birth weight or gestational age, neonatal morbidity or mortality. Fortunately, most of these outcomes are quite rare, and the sample sizes have not yielded sufficient power to detect small differences between groups. Many studies lack a strong theor- etical framework linking the intervention to the expected outcome. The weakness of the theoretical causal link between social support and low birth weight may account for this limited impact. Similar theoretical weaknesses were found in many of the studies included here, as well as in the review by Kendrick et al. (2000a).

One criticism of this body of literature is the difficulty in separating out the effects of home visiting in multipronged approaches. However, the Elmira study shows significant additive effects of home visiting. The Olds study is often criticized for the intensity of the intervention, yet some of the other studies of lesser intensity have not demonstrated a measurable effect.

Two further problems with this literature are the lack of description of the level of preparation of the 'nurses' who made the intervention, and the lack of description of what happens during the home visit. This makes any comparison of outcomes by nurse preparation or by type of intervention impossible. Robinson (1999) concurs with these limitations in her review of domiciliary home visiting.

\section{Conclusions}

Despite variations in the quality of research on home visiting, the positive direction of effect found through high-quality trials is generally supported by the results of weaker evaluations. Although there are limitations inherent in public health research, adequate evidence exists to enable conclusions to be drawn that home visiting by nurses has important impacts on many otherwise intransigent health problems.

There are many implications for practice and research arising from this review. In practice settings, home visiting interventions have not been effective in altering rates of low birth weight. However, adequate home visiting interventions (in intensity, duration and content) for pre- and postnatal women with risk factors are effective in improving a variety of physical, mental, social and developmental health outcomes, and in some cases have been shown to be cost-effective compared to control groups who are receiving normal care services. Home visiting allows for a programme delivery strategy for high-risk clients who may not access other means of care delivery. 
In relation to research implications, public health policy-makers, managers and clinicians want to know how intense an intervention needs to be in order to make a significant impact. Does it need to have the intensity and duration of the Elmira intervention? Can a paraprofessional be as effective as a baccalaureate-educated PHN? These are the questions that are of primary importance in the next generation of research related to home visiting as a strategy for delivering interventions by public health nurses. As a result of this review, several suggestions arise for researchers to consider when reporting their studies. One is to make very explicit how randomization was achieved. Another is to develop tracking strategies or other ways to achieve follow-up of at least $80 \%$ of the individuals who enter a study. Collecting information about possible confounders and controlling for these at the stage of data analysis would also improve the validity of the findings. These were the major weaknesses of this literature as a whole. Increased funding of public health nursing research will be necessary to enable the design and implementation of high-quality studies in which adequate sample sizes and follow-up are achieved. There is also a need for studies of outcomes which clients consider are important, rather than those solely predefined by the researcher. Finally, there is a tremendous need for cost analysis of public health interventions.

\section{Acknowledgements}

This review was supported financially by the Ministry of Health of Ontario, Public Health Branch. The ideas and conclusions presented in this paper do not necessarily represent those of the Ministry of Health.

We would like to thank the fourth-year nursing students Karen Yungblut and Amanda Hofsink, who assisted with the hand-searching of journals for this update. Maureen Dobbins also provided tremendous input in her previous role as project co-ordinator.

\section{References}

Achenbach, T. M., Phares, V., Howell, C. T., Rauh, V. A. and Nurcombe, B. 1990: Seven-year outcome of the Vermont
Intervention Program for Low-Birthweight Infants. Child Development 61, 1672-81.

Achenbach, T. M., Howell, C. T., Aoki, M. F. and Rauh, V. A. 1993: Nine-year outcome of the Vermont Intervention Program for Low Birth Weight Infants. Pediatrics 91, 45-55.

Black, M. M., Nair, P., Kight, C., Wachtel, R., Roby, P. and Schuler, M. 1994: Parenting and early development among children of drug-abusing women: effects of home intervention. Pediatrics 94, 440-48.

Brooten, D., Kumar, S., Brown, L. P., Butts, P., Finkler, S. A., Bakewell-Sachs, S., Gibbons, A. and Delivoria-Papdopoulos, M. 1986: A randomized clinical trial of early hospital discharge and home follow-up of very-low-birth-weight infants. New England Journal of Medicine 315, 934-39.

Canadian Public Health Association 1990: Community Health Public Health Nursing in Canada. Ottawa: Canadian Public Health Association.

Casiro, O. G., McKenzie, M. E., McFadyen, L., Shapiro, C., Seshia, M. M., MacDonald, N., Moffatt, M. and Cheang, M. S. 1993: Earlier discharge with community-based intervention for low birth weight infants: a randomized trial. Pediatrics 92, 128-34.

Ciliska, D., Hayward, S., Mitchell, A., Thomas, H., Dobbins, M. and Underwood, J. 1996: A systematic overview of the effectiveness of home visiting as a delivery strategy for public health nursing interventions. Canadian Journal of Public Health 87, 193-98.

Ciliska, D., Mastrilli, P., Ploeg, J., Hayward, S., Brunton, G. and Underwood, J. 1999: The effectiveness of home visiting as a delivery strategy for public health nursing interventions to clients in prenatal and postnatal period: a systematic review. Ontario: Effective Public Health Practice Project for the Public Health Branch, Ontario Ministry of Health.

Hayward, S., Ciliska, D., DiCenso, A., Thomas, H., Underwood, E. J. and Rafael, A. 1996: Evaluation research in public health: barriers to production and dissemination of outcomes data. Canadian Journal of Public Health 87, 413-17.

Holden, J. M., Sagovsky, R. and Cox, J. L. 1989: Counselling in a general practice setting: controlled study of health visitor intervention in treatment of postnatal depression. British Medical Journal 298, 223-26.

Kendrick D., Elkan, R., Hewitt, M., Dewey, M., Blair, M., Robinson, J., Williams, D. and Brummell, K. 2000a: Does home visiting improve parenting and the quality of the home environment? A systematic review and meta-analysis. Archives of Disease in Childhood 82, 443-51.

Kendrick, D., Hewitt, M., Dewey, M., Elkan, R., Blair, M., Robinson, J., Williams, D. and Brummell, K. 2000b: The effect of home visiting programmes on uptake of childhood immunization: a systematic review and meta-analysis. Journal of Public Health Medicine 22: 90-98.

Kitzman, H., Olds, D. L., Henderson, C. R., Hanks, C., Cole, R., Tatelbaum, R., McConnochie, K. M., Sidora, K., Luckey, D. W., Shaver, D., Engelhardt, K., James, D. and Barnard, K. 1997: Effect of prenatal and infancy home visitation by nurses on pregnancy outcomes, childhood injuries,

Primary Health Care Research and Development 2001; 2: 41-54 
and repeated childbearing: a randomized controlled trial. Journal of the American Medical Association 278, 644-52.

Olds, D. L. 1993: Effect of prenatal and infancy nurse home visitation on government spending. Medical Care 31, 155-74.

Olds, D. L., Henderson, C. R., Chamberlin, R. and Tatelbaum, R. 1986a: Preventing child abuse and neglect: a randomized trial of nurse home visitation. Pediatrics 78, 65-78.

Olds, D. L., Henderson, C. R., Tatelbaum, R. and Chamberlin, R. 1986b: Improving the delivery of prenatal care and outcomes of pregnancy: a randomized trial of nursing home visitation. Pediatrics 77, 16-28.

Olds, D. L., Henderson, C. R., Tatelbaum, R. and Chamberlin, R. 1988: Improving the life-course development of socially disadvantaged mothers: a randomized trial of nurse home visitation. American Journal of Public Health 78, 1436-45.

Olds, D. L., Henderson, C. R. and Kitzman, H. 1994: Does prenatal and infancy nurse home visitation have enduring effects on qualities of parental caregiving and child health at 25 to 50 months of life? Pediatrics 93, 89-98.

Olds, D. L., Eckenrode, J., Henderson, C. R., Kitzman, H., Powers, J., Cole, R., Sidora, K., Morris, P., Pettitt, L. M. and Luckey, D. 1997: Long-term effects of home visitation on maternal life course and child abuse and neglect. Journal of the American Medical Association 278, 637-43.

Olds, D. L., Henderson, C. R. Jr, Cole, R., Eckenrode, J., Kitzman, H., Luckey, D., Pettitt, L., Sidora, K., Morris, P. and Powers, J. 1998: Long-term effects of nurse home visitation on children's criminal and antisocial behavior: fifteen-year follow-up of a randomized controlled trial. Journal of the American Medical Association 280, 1238-44.
Oxman, A. D. (editor) 1992: Cochrane reviewers' handbook. Oxford: The Cochrane Collaboration.

Rauch, V. A., Achenbach, T. M., Nurcombe, B., Howell, C. T. and Teti, D. M. 1988: Minimizing adverse effects of low birthweight: four-year results of an early intervention. Child Development 59, 544-53.

Robinson, J. 1999. Domiciliary health visiting: a systematic review. Community Practitioner 72, 15-18.

Robinson, M., Israel, C., Parker, D., Lawrence, E., Smith, J., Dolby, S., Ring, W., Russell, G., Briscoe, J., Berry, J., House, A., Sawyer, J., Fry, K., Mercier, C., Hobday, A., Emond, A., Ravenhill, D. and Marlow, N. 1998: Randomised trial of parental support for families with very preterm children. Archives of Disease in Childhood: Fetal and Neonatal Edition 79, F4-F11.

Seitz, V., Rosenbaum, L. K. and Apfel, N. H. 1985: Effects of family support intervention: a ten-year follow-up. Child Development 56, 376-91.

Villar, J., Farnot, U., Barros, F., Victora, C., Langer, A. and Belizan, J. M. 1992: A randomized trial of psychosocial support during high-risk pregnancies. New England Journal of Medicine 327, 1266-71.

Wasik, B. H., Ramey, C. T., Bryant, D. M. and Sparling, J. J. 1990: A longitudinal study of two early intervention strategies: Project CARE. Child Development 61, 1682-90.

York, R., Brown, L. P., Samuels, P., Finkler, S. A., Jacobsen, B., Persely, C. A., Swank, A. and Robbins, D. 1997: A randomized trial of early discharge and nurse specialist transitional follow-up care of high-risk childbearing women. Nursing Research 46, 254-61.

Primary Health Care Research and Development 2001; 2: 41-54 